\title{
Repercussões do projeto UCA na qualidade de vida do trabalho em escolas públicas de Rolim de Moura - Rondônia
}

\author{
Repercussions of the UCA project in work quality of life in public \\ schools in Rolim de Moura - Rondônia (Brazil)
}

\author{
Marcos Tadeu Simões Piacentini \\ Fabricio Ziviani ${ }^{2}$ \\ Juliana Maria Magalhães Christino ${ }^{3}$ \\ Josmária Lima Ribeiro de Oliveira ${ }^{4}$
}

\section{Resumo}

O objetivo desse estudo é analisar as repercussões do Projeto Um Computador por Aluno na qualidade de vida no trabalho no contexto educacional. Nesse estudo comparado, de enfoque descritivo, adotou-se como estratégia investigativa a utilização de métodos mistos sequenciais com as variáveis de estudo embasadas no Modelo de Walton (1973). Constatou-se que os servidores da escola participante do Projeto UCA apresentam uma percepção significativamente negativa de QVT. Os fatores que mais influenciaram no resultado da pesquisa referem-se à insatisfação dos trabalhadores quanto às adequações ergonômicas do local de trabalho e aos recursos tecnológicos disponibilizados para o desempenho de suas atividades.

Palavras-chave: Inovação Tecnológica, Qualidade de Vida no Trabalho, Projeto UCA.

\begin{abstract}
The objective of this study is to analyze the impact of the Project One Computer per Student on the quality of life at work in the educational context. In this study compared, descriptive focus, a strategy was adopted to investigative use of mixed methods sequence with the variables of the study based on the model of Walton (1973). It was noted that the servers of school participant in the Project UCA present a perception significantly negative for QLW. The factors that most influenced the outcome of the research relate to the dissatisfaction of the workers about the adaptations of ergonomic workplace and the technological resources available for the performance of their activities.

Keyword: Technological Innovation, Quality of Work Life, Project UCA.
\end{abstract}

\footnotetext{
1 marcos.piacentini@gmail.com, Brasil. Professor do Centro Universitário Leonardo da Vinci - UNIASSELVI. Mestre em Administração pela Faculdade de Estudos Administrativos de Minas Gerais - FEAD-MG. Rua Otílio Macedo, 12, Olhos D'água, CEP: 30390-200 - Belo Horizonte, MG - Brasil.

2 contato@fabricioziviani.com.br, Brasil. Professor da Universidade Fundação Mineira de Educação e Cultura - FUMEC. Doutor em Ciências da Informação pela Universidade Federal de Minas Gerais - UFMG. Avenida Afonso Pena, 3880, Cruzeiro, CEP: 30130-009 - Belo Horizonte, MG - Brasil.

3 juliana.maga@uol.com.br, Brasil. Professora da Faculdade de Estudos Administrativos de Minas Gerais - FEAD-MG. Doutora em Administração pela Universidade Federal de Minas Gerais - UFMG. Rua Otílio Macedo, 12, Olhos D'água, CEP: 30390-200 - Belo Horizonte, MG - Brasil.

${ }^{4}$ professorajosmaria@gmail.com, Brasil. Professora da Faculdade de Estudos Administrativos de Minas Gerais - FEAD-MG. Doutora em Ciência da Informação pela Universidade Federal de Minas Gerais - UFMG. Rua Otílio Macedo, 12, Olhos D'água, CEP: 30390-200 - Belo Horizonte, MG - Brasil.
}

Recebido em 05.03.2013

Aprovado em 20.05.2014

Revista Administração em Diálogo

ISSN 2178-0080

Programa de Estudos Pós-Graduados em Administração

Pontifícia Universidade Católica de São Paulo 


\section{Introdução}

Desde tempos remotos, o homem tem buscado no trabalho a maneira pela qual se viabilizem as condições necessárias para adaptar a natureza às suas necessidades, transformando-a para a produção dos recursos necessários à qualidade e a continuidade de sua existência. A partir de então, o caminho percorrido pela humanidade até constituir-se na sociedade atual foi marcada por contínuas inovações nos meios para a produção de sua própria vida.

As novas tecnologias da informação e comunicação, popularmente chamadas de NTICs, resultam desse processo de desenvolvimento racional humano materializado também nos meios digitais que, progressivamente, tem influenciado cada vez mais o modo pelo qual o homem trabalha, se relaciona e vive.

Visando a construção de um projeto educacional que contemple essas demandas, o Governo Federal em parceria com outros entes governamentais, vem executando desde 2007 a implantação do Projeto Um Computador por Alunos - UCA, cujo objetivo é promover a melhoria da educação nacional e a inclusão digital de alunos e professores da rede pública de ensino por meio da integração do conteúdo didático formal a uma nova metodologia que inicie os alunos nos processos tecnológicos indispensáveis à construção da cidadania e para a inserção profissional, viabilizando como material escolar, um laptop para ser utilizado na rotina escolar diária de cada aluno matriculado nas escolas contempladas pelo projeto. Um Computador por Aluno (UCA, 2OI2).

Contudo, a utilização do computador mediando a prática docente em sala de aula pode representar mais do que a inserção de um equipamento eletrônico como ferramenta pedagógica no ambiente de ensino, pois à medida que as exigências impostas ao sistema educacional para corresponder às demandas da sociedade tornam-se mais complexas, as atividades desenvolvidas pelos trabalhadores também tendem a aumentar de volume e em grau de complexidade, ou ainda em níveis aos quais os funcionários não estão aptos a responder.

Tal situação tem desafiado os gestores de sistemas de ensino a compreenderem a relação existente entre a inovação tecnológica no contexto educacional e a qualidade de vida dos trabalhadores para prevenir ou atenuar os efeitos decorrentes, que podem influir no desempenho de suas atividades. 
Nestes termos, este trabalho compila os dados obtidos em pesquisa para dissertação de mestrado, cuja natureza descritiva, com enfoque quanti-qualitativo, resulta de um estudo comparativo do diagnóstico da percepção de Qualidade de Vida no Trabalho QVT dos servidores de duas instituições publicas de ensino, uma das quais contemplada pelo Programa UCA, com a finalidade de averiguar se há uma discrepância entre os resultados dos servidores de instituições públicas de ensino.

\section{Qualidade de Vida No Trabalho}

A Qualidade de Vida no Trabalho (QVT) é um ramo da ciência comportamental humana e refere-se a uma linha de estudos que se ocupa especificamente na observação dos aspectos vinculados ao bem-estar dos indivíduos decorrente das circunstâncias ligadas ao seu trabalho (FERNANDES, I996).

Muito embora possa ser considerada uma linha de pesquisa bastante desenvolvida, observa-se uma diversidade de conceitos que, implícita ou explicitamente, resultam de diferentes visões acerca do trabalhador, da concepção das atividades laborais, da gestão do trabalho, entre outros. (MEDEIROS; FERREIRA, 2OII).

Ao examinar a literatura especializada sobre o tema, Fernandes (I996, p. 43) destaca que, independentemente da maneira como cada autor focaliza o assunto, uma característica parece comum nos conceitos "[...] a meta principal de tal abordagem volta-se para a conciliação dos interesses dos indivíduos e das organizações, ou seja, ao mesmo tempo em que melhora a satisfação do trabalhador, melhora a produtividade da empresa".

Entre os principais autores referenciados na literatura científica, destaca-se o trabalho produzido por Richard Walton (1973). O autor procurou descobrir nas organizações, elementos associados à satisfação e bem-estar desse trabalhador na execução da sua tarefa e que foram "[...] negligenciados pelas sociedades industriais em favor do avanço tecnológico, da produtividade e do crescimento econômico” (WALTON, I973, p.II).

Esses elementos foram agrupados por Walton (I973) em oito categorias como critérios para analisar a Qualidade de Vida no Trabalho, detalhados a seguir: 
I. Compensação justa e adequada: Nesta categoria é estabelecida uma medida para a QVT em relação ao salário recebido pelo trabalhador, e esta subdividida em: a) Remuneração adequada; b) Equidade interna, e; c) Equidade externa.

2. Condições de Trabalho: Esta categoria relaciona o nível de satisfação do trabalhador com as condições encontradas em seu local de trabalho, e se subdivide em: a) Jornada de trabalho; b) Carga de trabalho; c) Ambiente físico; d) Material e equipamento; e) Ambiente saudável, e; f) Estresse.

3. Uso e desenvolvimento de capacidades: tem por objetivo mensurar a QVT em relação às possibilidades do empregado por em prática os seus conhecimentos e suas habilidades profissionais. Esta categoria esta subdivida em cinco critérios: a) Autonomia; b) Significado da tarefa; c) Identidade da tarefa; d) Variedade da habilidade, e; f) Retro informação.

4. Oportunidade de crescimento e segurança: busca medir a QVT considerando a segurança se seu emprego e as oportunidades de ascensão profissional na empresa. Os critérios utilizados são: a) Possibilidade de carreira; b) Crescimento pessoal, e; c) Segurança de emprego.

5. Integração social na organização: esta categoria tem a finalidade de avaliar a QVT observando o grau de harmonia na convivência social entre os trabalhadores da organização. Pode ser medido por meio dos critérios: a) Relacionamento; b) Igualdade de oportunidades, e; c) Senso comunitário.

6. Constitucionalismo: Esta categoria associa a QVT ao nível de observação dos direitos dos empregados na instituição. Os critérios analisados nesta categoria são: a) Direitos trabalhistas; b) Privacidade pessoal; c) Liberdade de expressão, e; d) Normas e rotinas.

7. Trabalho e espaço total de vida: avaliar o grau de satisfação do operário em relação à interferência que o trabalho exerce em sua vida privada. $\mathrm{O}$ autor sugere a mensuração por meio de dois critérios: a) Papel balanceado do trabalho; b) Horário de entrada e saída do trabalho.

8. Relevância social da vida no trabalho: relaciona a QVT à imagem institucional da empresa a partir da percepção do funcionário em relação à responsabilidade social da organização. Admite quatro critérios: a) Imagem da 
instituição; b) Responsabilidade social da instituição; c) Responsabilidade social pelos serviços, e; d) Responsabilidade social pelos empregados.

\section{Projeto Um Computador Por Aluno - UCA}

No Brasil, a política de utilização de laptops educacionais tem correspondido ao que sugere a iniciativa internacional da organização OLPC One Laptop Per Children.

A OLPG é uma instituição não governamental, criada no ano de 200I por pesquisadores americanos do Massachusetts Institute of Technology - MIT, com o objetivo incentivar a inclusão digital dos alunos de escolas públicas. A estratégia principal para atingir este objetivo é a conscientização de entidades governamentais para a elaboração de políticas públicas na educação que contemplem a distribuição de um laptop educacional por aluno. One Laptop Per Children - Brasil (OLPC BRASIL, 2OI2).

Durante o Fórum Econômico Mundial ocorrido janeiro de 2005 em Davos, Suíça, a proposta do OLPC foi apresentada ao governo brasileiro. Neste mesmo ano, os idealizadores do OLPG Nicholas Negroponte, Seymour Papert e Mary Lou Jepsen estiveram ao Brasil para expor o projeto em detalhes (VILARDO, 2005).

Inicialmente, o governo brasileiro instituiu um grupo interministerial responsável por avaliar a proposta e a viabilização do projeto, e em 20o6, o Ministério da Educação em conjunto com o Ministério da Ciência e Tecnologia fizeram o lançamento oficial do Projeto UCA (SANTOS; BORGES, 2009) e, no período compreendido entre 2008 e 2OIO, foi empreendida à primeira fase em que fizeram parte cinco escolas públicas nos municípios de São Paulo-SP, Porto Alegre-RS, Palmas-TO, Piraí-RJ e Brasília-DF. A implantação do projeto nesses municípios contou com o apoio das universidades federais que ficaram responsáveis pelo suporte tecnológico, capacitação dos educadores e pela análise da implantação do Projeto UCA (UCA, 2OI2).

Em sua segunda fase, denominada fase Piloto, o Projeto UCA teve início em 2OIO e distribuiu I5O.OOO laptops educacionais atendeu a 3 OO unidades escolares distribuídas pelo território nacional, e mais todas as escolas da rede publica de ensino dos municípios de Barra dos Coqueiros - SE, Caetés - PE, Santa Cecília do Pavão - PR, São João da Ponta - PA, Terenos - MS e Tiradentes - MG, o que caracterizou uma nova 
formatação do projeto denominado Cidades UCA Total (SCHNEIDER; SANTAROSA; CONFORTO, 2OII).

Nesta fase, além dos laptops, as escolas participantes do projeto receberam curso de formação pedagógica para os docentes e gestores, também foram entregues equipamentos indispensáveis para a conexão com a internet (BONA et al, 2OI2).

\section{Impacto das inovações tecnológicas no trabalho}

Inovação tecnológica é um conceito abrangente, geralmente associado à implementação de maquinas ou equipamentos sofisticados, mas que também pode se aplicado à novas formas de realização de tarefas, mudanças em produtos, ou ainda a novos processos ou procedimentos (REIS, 2004).

Na visão de Tidd, Bessant e Pavitt (2008) as mudanças ocorridas nas empresas pela inovação podem ser classificadas em: a) Inovações de produtos: agrupam as mudanças que ocorrem nos produtos ou serviços oferecidos pela empresa; b) Inovações de processos: agrupam mudanças na maneira como os produtos ou serviços são produzidos; c) Inovações de posições: agregam as mudanças que ocorrem no contexto em que os produtos ou serviços são introduzidos; d) Inovações de paradigmas: resultam das mudanças que ocorrem nos modelos mentais subjacentes que norteiam o funcionamento da empresa.

Contudo, Albuquerque (2005) afirma que a introdução de uma nova tecnologia pode produzir uma série de consequências, tais como modificações nas relações de trabalho, obsolescência de ocupações e categorias profissionais e confronto de questões éticas e políticas.

Deste pressuposto, as novas tecnologias da informação e comunicação podem ser entendidas como sendo uma inovação tecnológica afetam diretamente os trabalhadores produzindo uma série de efeitos sociais que repercutem na qualificação para o trabalho, nas condições para realização das tarefas, na saúde do trabalhador e nas políticas de ocupação. Em muitos países a utilização de novas tecnologias ocasionou a redução do numero de empregos (HERÉDIA, 2007).

Este mesmo ponto de vista é compartilhado com Netz (2005) que, ao investigar o impacto das novas tecnologias no trabalho bancário brasileiro, constatou que: a) o ganho 
da produtividade dificulta a geração de novos postos de trabalho e aumenta o numero de demissões; b) o aumento do controle faz com que o trabalhador não conheça com profundidade o seu processo de trabalho; c) a qualificação é mais exigida como parte do processo de seleção do que para o exercício da maior parte das tarefas.

Netz (2005) observou ainda que as pessoas que utilizam do serviço bancário executam algumas operações sem, no entanto receber qualquer remuneração, ao passo que ainda são responsabilizados por eventuais erros de digitação que possam ocorrer. Diante disso conclui que as novas tecnologias não apenas impactam a relação capitaltrabalho, como também fazem surgir um novo tipo de trabalho não remunerado.

$\mathrm{Na}$ visão de Pilatti (2007), os avanços tecnológicos não convergem necessariamente para a qualidade de vida do trabalhador. Em seu trabalho, o autor identificou que a exigências que se estabelecem aos trabalhadores extrapolam o ambiente laboral e afetam a qualidade de vida do trabalhador dentro e fora do trabalho. A atual exigência de qualificação para a manutenção da empregabilidade contribuiu para a percepção que o trabalho já não é para todos, é somente aos especialmente talentosos.

Neste raciocínio, Souza e Ziviani (2OIO) contribuem afirmando que as constantes mudanças no desempenho das tarefas motivam o aumento das cobranças os níveis de pressão sobre o trabalhador, aumentando a jornada de trabalho, intensificando o cansaço físico, mental e até emocional do trabalhador, ocasionando o estresse ocupacional, processo que culmina na ausência de qualidade de vida no trabalho.

No tocante à incidência de doenças relacionadas especificamente ao uso do computador no trabalho, Azevedo e Kitamura (2007) indicam que por melhor que seja a ergonomia física do trabalho, a dinâmica desse tipo de trabalho ocasiona dores e fadigas musculares, podendo causar lesões musculoesqueléticas de membros superiores. No entanto, estes efeitos podem ser minimizados por meio da reformulação do ambiente de trabalho pela utilização de cadeiras ajustáveis em altura e inclinação, mesas apropriadas, apoio para os pés, apoio para as mãos entre outros, conforme salientam os autores.

Referente aos impactos ocasionados pela inserção das novas tecnologias de comunicação e informação no trabalho em ambiente escolar Carboni (2006) identificou que os professores se sentem inseguros e buscam evitar a utilização dos computadores. A falta de um equipamento próprio, a falta de prática e treinamento, o receio que os alunos 
tenham maior conhecimento sobre o computador que eles próprios, o medo por causar algum dano ao equipamento ou serem mal sucedidos, a vergonha pela falta de domínio da ferramenta estariam entre as justificativas.

Carboni (2006) também constatou que os imprevistos em relação à parte técnica dos equipamentos, além de ocasionar inseguranças e transtornos, prejudicam a execução das tarefas planejadas resultando em problemas na regência da aula, exigindo que o professor esteja preparado para duas aulas diferentes, caso seja necessário.

Sob este aspecto, o estudo realizado por Assunção e Oliveira (2009) constata que a evolução dos sistemas no ambiente escolar promovem mudanças na gestão e organização do trabalho, resultando no aumentando da quantidade de tarefas realizadas em uma mesma jornada de trabalho afetando a qualidade do serviço e do trabalho.

Fixando-se ainda o olhar nos estudos que associam as NTICs com a intensificação do trabalho, encontra-se a pesquisa feita por Arruda (2004), no qual o autor vincula a existência ou não de intensificação do trabalho docente à maneira como o trabalhador adota a tecnologia, atribuindo às novas tecnologias o uso mais inovador ou mais tradicional. O autor afirma estar ocorrendo intensificação do trabalho entre os docentes apenas naqueles que fazem o manuseio mais inovador das tecnologias, entretanto, foi observada uma redução da carga de trabalho entre os docentes que utilizavam as novas tecnologias como utilizavam as tecnologias anteriores, ou seja, nas funções de copiadora, máquina de datilografia, entre outros. Nestes professores a resistência ao uso inovador das NTICs estaria ligada ao aumento do tempo de trabalho não remunerado, visto terem que adquirir determinadas habilidades especificas sem uma contrapartida salarial.

Oliveira (2OIO) concorda que a utilização das NTICs produz a intensificação do trabalho docente, entretanto, com base na analise do discurso de um grupo de professores, averiguou que isso pode ocorrer apenas no momento de criação de suas estratégias de ensino com o computador e do material pedagógico. Uma vez arquivado em seu computador, já não ocorre a intensificação do trabalho, pois, estes professores, não se desgastam preparando uma nova atividade e utilizam em varias ocasiões o mesmo material, às vezes sem mesmo fazerem poucas adequações ao trabalho original. Diante 
disso conclui que "o computador pode estar representando um extermínio progressivo da criatividade docente" (Oliveira, 2OIO, p. 92).

Pontuando esta argumentação, Almeida (2007) não culpa a tecnologia pela degradação da qualidade de vida do trabalhador. De acordo com o autor a tecnologia em si mesma é neutra, sem identidade, mas a utilização é ideológica, pois depende da vontade humana. O paradoxo da tecnologia é que ao mesmo tempo em que pode facilitar a vida também pode exterminá-las.

\section{Contribuição da pesquisa ao Modelo de Walton}

Objetivando-se avaliar o nível de satisfação de Qualidade de Vida no Trabalho dos servidores de instituições de ensino em ambiente adaptado para a utilização frequente do computador como recurso didático em tempo integral nos moldes do Projeto UCA, propõe-se contribuir para o Modelo de Walton (I973) expandindo uma nova categoria conceitual para mensuração da Qualidade de Vida no Trabalho ao instrumento de pesquisa adaptado e validado por Carvalho-Freitas (2007).

Esta nova categoria contempla três critérios que consideram o impacto das novas tecnologias da informação e comunicação no ambiente de trabalho e sua repercussão na vida do trabalhador.

9. Impacto das NTICs no trabalho: associa a QVT às repercussões das mudanças tecnológicas no ambiente de trabalho e na saúde do trabalhador dentro e fora da organização. Admite quatro critérios: a) Renda associada à capacitação; b) Reformulação do ambiente de trabalho; c) Intensificação do trabalho, descritos em pormenores a seguir:

a) Renda associada à capacitação - Frente às constatações apontadas por Pilatti (2007) e por Netz (2005), nas quais a capacitação é uma exigência para a utilização das novas tecnologias, haja vista que a inovação tecnológica pode tornar o trabalho mais sofisticado, e que os profissionais tem priorizado parte do tempo reservado ao descanso para sua formação profissional e manutenção da sua empregabilidade, relaciona-se a QVT à percepção do trabalhador em relação ao incentivo oferecido pela empresa para sua capacitação profissional. 
b) Preservação da saúde - Azevedo e Kitamura (2007) e Oliveira (2007) comprovaram que a utilização do computador no trabalho afeta a saúde do trabalhador. De acordo com os autores, a organização física do trabalho concorre para a redução das dores e fadigas musculares ocasionadas pelas novas tecnologias. As mudanças no desempenho das atividades que não observam os fatores ergonômicos Souza e Ziviani (2OIO) favorecem o surgimento do estresse ocupacional afetando qualidade de vida no trabalho. Assim sendo, o desconhecimento das doenças que decorrem da inovação do ambiente de trabalho agrava a qualidade de vida do trabalhador. O entendimento Assim relaciona-se a QVT à percepção do trabalhador sob dois aspectos: em relação às informações prestadas pelo empregador sobre as doenças ocupacionais ligadas à utilização das tecnologias; e em relação à reformulação ou adaptação dos postos de trabalho ao funcionamento do organismo humano.

c) Intensificação do trabalho - A gestão e a organização do trabalho sofrem mudanças diante da informatização do ambiente escolar. Entre estas mudanças, os estudos de Oliveira (20IO), Assunção e Oliveira (2009), Carboni (2006), Arruda (2004), confirmam a intensificação do trabalho e sua influencia na qualidade do serviço e do trabalho. Dessa forma, por este critério associa-se a QVT à percepção do trabalhador diante do acúmulo de tarefas que decorrem da utilização do computador no local de trabalho.

\section{Procedimento Metodológico}

A compreensão de que na ciência, para se chegar a um fim almejado é necessário o uso de uma metodologia, é preconizada por Gil (I999) ao elucidar que na construção de uma pesquisa de cunho científico se faz necessário a utilização de um arcabouço metodológico adequado, que se consubstancia no conjunto de procedimentos técnicos e mentais empregados na investigação que concorrem para o alcance dos objetivos definese o método científico.

Deste modo, para construir o quadro metodológico proposto para este estudo, elege-se um raciocínio dedutivo que, do ponto de vista dos objetivos dessa pesquisa de caráter prático, define-se como enfoque descritivo que de acordo com Gil (I999) é o tipo 
de pesquisa que tem por objetivo descrever as características da população estudada ou estabelecer relações entre as variáveis. Em relação aos procedimentos da investigação, estabelece-se o método comparativo.

Este trabalho combina estratégias de análise quantitativa e qualitativa. Os autores Gomes e Araújo (2005) defendem o caráter complementar dos métodos quantitativos e qualitativos e sua utilização nos estudos em Administração, haja vista ser esta uma área científica com elevado nível multidisciplinar. Assim sendo, os objetos de estudo em Administração são de difícil entendimento, carecendo de uma metodologia que envolva vários aspectos.

Considerando a abordagem mista de métodos, a coleta de dados da pesquisa foi feita em duas fases, sendo na primeira desenvolvida uma abordagem quantitativa. $\mathrm{Na}$ segunda fase da pesquisa utilizou-se de uma abordagem qualitativa, a amostragem foi proposital e o instrumento de pesquisa utilizado foi a entrevista semiestruturada. A delimitação do universo de sujeitos da $2^{\text {a }}$ fase da pesquisa considerou o resultado da pesquisa quantitativa.

A população alvo da pesquisa, em sua I ${ }^{\mathrm{a}}$ fase, foi composta por todo o grupo de trabalhadores que desempenham suas atividades profissionais em duas escolas estaduais de ensino fundamental, ambas localizadas no município de Rolim de Moura - RO. O processo de escolha da primeira instituição de ensino deu-se por amostragem intencional por ser uma das sete escolas no Estado de Rondônia contempladas pelo projeto UCA. A segunda instituição, não contemplada pelo Projeto UCA, foi escolhida a partir do critério de maior semelhança com as características da primeira instituição.

\section{Instrumento de pesquisa}

A coleta dos dados na $\mathrm{I}^{\mathrm{a}}$ fase foi realizada por meio de um questionário visando identificar o perfil demográfico da população estudada e a sua percepção em relação à Qualidade de Vida no Trabalho.

O questionário utilizou a Escala de Likert de escolha fechada, contínua e crescente composta por cinco níveis: $\mathrm{I}=$ muito insatisfeito; $2=$ insatisfeito; $3=$ nem satisfeito nem satisfeito; 4 = satisfeito; $5=$ muito satisfeito. $\mathrm{O}$ instrumento de pesquisa é composto por questões fechadas embasado no Modelo Teórico de Walton (I973), foi 
adaptado e validado por Carvalho-Freitas (2007) por meio de análise de precisão através do método de consistência interna, coeficiente alpha de Crombach, o qual apresentou consistência interna superior a o,8I indicando, conforme Malhotra (2OOI), confiabilidade satisfatória da consistência interna.

Os dados empíricos da pesquisa na $2^{\text {a }}$ fase foram levantados através de entrevistas semiestruturadas. As entrevistas foram realizadas na escola A, o roteiro foi composto basicamente de sete perguntas e o conteúdo das perguntas abordou aspectos do ambiente de trabalho dos servidores. Participaram da entrevista, servidores dos setores administrativo e pedagógico. Durante as entrevistas desta pesquisa, preocupouse em deixar o entrevistado à vontade para que pudesse melhor ser expressar, porém mantendo-se o foco no roteiro das questões previamente elaboradas.

\section{Técnica de análise de dados}

A análise da percepção do corpo funcional de cada uma das escolas foi conduzida de modo a estabelecer a percepção geral de QVT de cada escola, e pela comparação entre essas percepções. Assim, para verificar a existência de associação entre a frequência dos dados demográficos e ocupacionais e dos com relação à execução do projeto UCA entre as duas escolas, foi utilizado o teste de Qui-Quadrado, sendo realizado via simulação Monte Carlo (AGRESTI, 2002) quando as frequências esperadas de alguma das variáveis eram menores do que cinco. O teste Qui-Quadrado também foi empregado para verificar se na escola A, havia evidências de associação entre as formas de participação no projeto com os cargos e setores da escola. O nível de significância adotado no trabalho foi de $5 \%$. Para o tratamento estatístico dos dados foi utilizado o software estatístico R versão 2.I5.O.

Quanto à análise de conteúdo, inicialmente procedeu-se a transcrição literal das entrevistas, que foram todas gravadas, seguida de leitura, fragmentação e reorganização dos fragmentos assinalados, ou seja, dividiu-se o discurso do entrevistado em unidades de significação para então começar o processo de interpretação articulando as unidades entre si, para então formular hipóteses explicativas do problema, conforme sugere Duarte (2004). 


\section{Apresentação e análise dos dados}

Objetivando facilitar a interpretação das informações, optou-se por apresenta-las em três enfoques analíticos: análise descritiva, análise estatística e análise interpretativa. As análises descritiva e estatística dizem respeito fase quantitativa da pesquisa, e a análise interpretativa corresponde a analise dos dados levantados na fase qualitativa.

A análise descritiva dos dados levantados na fase quantitativa compila os dados demográficos e ocupacionais dos sujeitos da pesquisa e foram divididos de forma a apresentar os dados demográficos e ocupacionais e a participação dos servidores das escolas com a execução do Projeto UCA.

$\mathrm{Na}$ análise dos dados demográficos e ocupacionais, as variáveis foram apresentadas de forma estratificada entre as escolas A e B, possibilitando conhecer o perfil de cada escola com relação às variáveis estudadas.

Foram entrevistadas, nesta fase da pesquisa, 40 pessoas da Escola A e 36 pessoas da Escola B. Verificando a proporção como os dados se apresentam nas escolas investigadas pode-se concluir que o perfil dos dados demográficos e ocupacionais não se difere entre elas.

Destaca-se que os servidores que desenvolvem suas funções nas escolas estudadas estão predominantemente na faixa de 40 a 50 anos e possuem, em média, uma grande experiência de trabalho, uma vez que menos de $20 \%$ dos respondentes possuem até seis anos de trabalho no serviço público.

A análise estatística dos dados apurou que o indicador Compensação Justa e Adequada é significativamente negativo com média-O,I66 para a escola A e para escola B $-\mathrm{O}, \mathrm{II} 5$.

Para o indicador "Condições de Trabalho" averiguou-se que as medidas contém em seu intervalo de confiança o zero, tanto para a escola A (-O,OO) $)$, como para a escola B (o,o89) evidenciando que tanto os servidores da escola A quanto da escola B se sentem Nem Satisfeitos e Nem Insatisfeitos com relação às condições de trabalho, ou seja, os servidores estão indiferentes às amplas condições de trabalho nas escolas.

O indicador "Uso e Desenvolvimento de Capacidades" mostrou-se significativamente positivo tanto para a Escola A quanto para a Escola B, cujas médias 
atingiram respectivamente 0,233 e o,33I, evidenciando em ambas as escolas os servidores se sentem Satisfeitos com o uso e desenvolvimento de capacidades.

Ao que se refere ao indicador "Oportunidade de Crescimento e Segurança”, as escolas obtiveram médias próximas ao zero do intervalo de confiança. A Escola A obteve média 0,O73 enquanto que a Escola B atingiu o,Io9, evidenciando em ambas as escolas os servidores se sentem Nem Satisfeitos e Nem Insatisfeitos com a oportunidade de crescimento e segurança.

Analisando as medidas estatísticas para o indicador "Integração Social na Organização" constatou-se que para ambas as escolas o indicador mostrou-se significativamente positivo, uma vez que para a escola A, a média obtida foi o,515, e para a escola $\mathrm{B}$, a média atingiu o escore o,6r3, porém na escola $\mathrm{B}$, pode-se inferir que os servidores estão muito satisfeitos, uma vez que o limite inferior do intervalo de confiança é maior que 0,5 .

Referente ao indicador "Constitucionalismo", este se mostrou significativamente positivo, tanto para a escola A, o, $35^{8}$, quanto para a escola $\mathrm{B}, \mathrm{O}, 39^{8}$, evidenciando que em ambas as escolas os servidores se sentem Satisfeitos com o Constitucionalismo.

Esta mesma tendência também é observada no indicador "Trabalho e Espaço Total de Vida", pois mostra-se significativamente positivo para os servidores da escola A, que obteve média o,3I9, assim com para os servidores da escola B, cuja média foi de o,378, evidenciando que os servidores de ambas as escolas se sentem satisfeitos com o Trabalho e Espaço Total de Vida.

O indicador "Relevância Social da vida no trabalho" também se evidenciou significativamente positivo para as duas escolas. As médias obtidas para as Escolas A e B foram, respectivamente, 0,423 e $0,5 \mathrm{O} 7$, evidenciado que em ambas as escolas os servidores se sente Satisfeitos com a relevância social da vida no trabalho.

Entretanto, o indicador "Impactos das NTICs no Trabalho" mostrou-se significativamente negativo para os servidores da escola A, -O,O77, evidenciando que os servidores se sentem Insatisfeitos, destacando-se os itens “Adequações ergonômicas no meu local de trabalho para utilização do computador nas atividades que realizo", e 
"Recursos tecnológicos que a instituição me oferece para desempenhar minhas atividades" como sendo os quesitos que se mostraram mais significativamente negativos.

Já para os servidores da escola B, o indicador "Impactos das NTICs no Trabalho" mostrou-se significativamente positivo o,o8I, evidenciando que os servidores desta escola se sentem Satisfeitos com os Impactos das NTICs no Trabalho. Em relação a este quesito a escola B apresentou estatisticamente ( $\mathrm{p}$-valor $<0,05)$ uma maior pontuação no indicador "Impactos das NTICs no Trabalho" quando comparado com a escola A. Logo, conclui-se que com relação aos Impactos das NTICs no Trabalho os servidores da escola B se sentem mais satisfeitos que os servidores da escola A.

A tabela a seguir ilustra estas informações, facilitando as comparações entre os indicadores.

Tabela I - Comparação dos indicadores de QVT entre as escolas A e B

\begin{tabular}{|c|c|c|c|c|}
\hline Variáveis & Escola & $\mathbf{N}$ & Média & P-valor \\
\hline \multirow{2}{*}{ Compensação Justa e Adequada } & A & 40 & $-0,166$ & \multirow{2}{*}{0,473} \\
\hline & $\mathrm{B}$ & 36 & $-0,115$ & \\
\hline \multirow{2}{*}{ Condições de Trabalho } & A & 40 & 0,007 & \multirow{2}{*}{0,333} \\
\hline & $\mathrm{B}$ & 36 & 0,089 & \\
\hline \multirow{2}{*}{ Uso e Desenvolvimento de Capacidades } & A & 40 & 0,233 & \multirow{2}{*}{0,39} \\
\hline & B & 36 & 0,331 & \\
\hline \multirow{2}{*}{ Oportunidade de Crescimento e Segurança } & $A$ & 40 & 0,073 & \multirow{2}{*}{0,746} \\
\hline & $\mathrm{B}$ & 36 & 0,109 & \\
\hline \multirow{2}{*}{ Integração Social na Organização } & A & 40 & 0,515 & \multirow{2}{*}{0,042} \\
\hline & B & 36 & 0,613 & \\
\hline \multirow{2}{*}{ Constitucionalismo } & A & 40 & 0,358 & \multirow{2}{*}{0,437} \\
\hline & $\mathrm{B}$ & 36 & 0,398 & \\
\hline \multirow{2}{*}{ Trabalho e Espaço Total de Vida } & A & 40 & 0,319 & \multirow{2}{*}{0,839} \\
\hline & B & 36 & 0,378 & \\
\hline \multirow{2}{*}{ Relevância Social da Vida no Trabalho } & A & 40 & 0,423 & \multirow{2}{*}{0,114} \\
\hline & B & 36 & 0,507 & \\
\hline \multirow{2}{*}{ Impactos da NTIC no Trabalho } & A & 40 & $-0,077$ & \multirow{2}{*}{0} \\
\hline & $\mathrm{B}$ & 36 & 0,081 & \\
\hline
\end{tabular}

Fonte: Dados da pesquisa

Analisando os dados da pesquisa pode-se concluir que para as escolas A e B, os indicadores "Uso e Desenvolvimento de Capacidades", "Integração Social na Organização", "Constitucionalismo", "Trabalho e Espaço Total de Vida”, "Relevância Social da vida no trabalho" são significativamente positivos evidenciando que os servidores dessas escolas se sentem Satisfeitos com estes indicadores. 
Os indicadores "Condições de Trabalho", "Oportunidade de Crescimento e Segurança” demonstram que os servidores das escolas A e B não estão Nem Satisfeitos e Nem Insatisfeitos com relação a estes indicadores.

O indicador "Compensação Justa e Adequada" apresenta-se significativamente negativo evidenciando que os servidores se encontram insatisfeitos com relação a este indicador. O setor pedagógico e o cargo de professor é o que apresenta o menor nível de satisfação para esse indicador em ambas as escolas.

O único indicador que se apresentou discrepante foi "Impactos das NTICs no Trabalho" cujos níveis polarizaram-se em significativamente positivo para a escola B e significativamente negativo para a escola A.

Para verificar a diferença dos indicadores entre os setores da escola A, foi realizado o teste de Kruskal-Wallis. De acordo com a tabela a seguir, observa-se uma diferença significativa para o indicador "Impactos das NTICs no Trabalho".

Tabela 2 - Diferença entre os setores da Escola A

\begin{tabular}{|c|c|c|c|c|}
\hline Indicador & Setor & $\mathbf{N}$ & Média & P-valor \\
\hline \multirow{3}{*}{ Impactos da NTIC no Trabalho } & Administrativo & 9 & $-0,08$ & \multirow{3}{*}{0,017} \\
\hline & Pedagógico & 20 & $-0,14$ & \\
\hline & Serviços Gerais & 11 & 0,03 & \\
\hline
\end{tabular}

Fonte: Dados da pesquisa

Para verificar entre quais setores o indicador se difere, foram realizadas as comparações múltiplas via teste de Nemenyi. Dessa forma, pode-se verificar que para o indicador "Impactos das NTICs no Trabalho" se difere significativamente a comparação, sendo no setor pedagógico o menor índice médio de satisfação.

A verificação da diferença dos indicadores entre os cargos foi realizada pela aplicação do teste de Kruskal-Wallis, sendo significativo para o indicador "Impactos da NTICs no Trabalho" (P-valor $<=0,05)$, conforme se pode observar na tabela a seguir. 
Tabela 3 - Diferença entre os cargos da Escola A

\begin{tabular}{|c|l|c|c|c|}
\hline \multicolumn{1}{|c|}{ Indicador } & Cargo & $\mathbf{N}$ & Média & P-valor \\
\hline \multirow{3}{*}{ Impactos da NTIC no Trabalho } & Diretor & 6 & $-0,16$ & \\
\cline { 2 - 5 } & Professor & 16 & $-0,17$ & \multirow{2}{*}{0,002} \\
\cline { 2 - 5 } & Secretário & 3 & $-0,05$ & \\
\cline { 2 - 5 } & Outros & 15 & 0,04 & \\
\hline \hline
\end{tabular}

Fonte: Dados da pesquisa

Constata-se, portanto que, na análise da fase quantitativa, a Qualidade de Vida no Trabalho dos servidores da escola participante do Projeto UCA apresentou menor índice que o da escola não participante do projeto. De acordo com o modelo teórico da pesquisa o indicador "Impactos das NTICs no Trabalho" é o único indicador que contrasta na comparação entre as escolas, sendo que o setor com maior influencia neste resultado é o pedagógico e o cargo de professor é o que apresenta o menor nível entre os demais servidores da escola.

\section{Análise interpretativa}

Considerando-se o resultado da fase quantitativa, foi aplicada técnica de entrevista semiestruturada e dirigidas aos servidores que ocupam os cargos de diretor, coordenador e professor, com o intuito de aprofundar o entendimento em relação à variação nos dois indicadores mais expressivos da categoria "Impactos das NTICs no Trabalho" que impactaram negativamente a percepção de QVT da escola A.

Inicialmente foi possível observar que o processo de implantação do projeto UCA na escola teve inicio em 2009 quando ocorreu a adesão da escola ao projeto, ao final de 2OIO, após adequações das estruturas físicas para o armazenamento e guarda dos equipamentos, ocorreu a entrega dos laptops. Porem, apenas em maio de 2OII, após concluir o cadastramento dos laptops, a escola agregou a nova tecnologia no cotidiano escolar.

Os servidores participantes da pesquisa, quando perguntados sobre o processo de implementação do Projeto UCA na escola, criticaram muito a demora na chegada dos equipamentos. As palavras "ansiedade”, "expectativa”, "apreensão" e "desinformação", intercaladas às expressões "não chega nunca" e "vem e não vem", foram os sentimentos 
descritos por eles ao aguardarem a chegada do Projeto na escola, para expressar suas preocupações e descréditos.

O treinamento dos servidores teve início no final do ano de 20IO, com a chegada dos laptops. A este respeito, a percepção geral dos entrevistados é a de satisfação com a capacitação que atualmente dispõe para a realização das suas atividades. No entanto, quando questionados se as informações oferecidas durante as oficinas ou reuniões de formação quanto à utilização do comutador em sala de aula atenderam à sua expectativa, os entrevistados declararam que os treinamentos foram poucos e rápidos, não considerando ainda os diferentes níveis de conhecimento que dispunham em relação ao computador.

Estas declarações dos entrevistados pode indicar um défice na formação causado por um diagnóstico mau feito, ou por não terem sido considerados os diferentes níveis de conhecimentos prévios de informática dos servidores diretamente ligados à execução do projeto, com o agravante do pouco tempo destinados para a participação nos encontros de capacitação.

Ao indagar-se pela quantidade de vezes que o laptop é utilizado em sala de aula, os servidores relataram que durante os encontros de formação dos quais participaram, não teria sido estipulado uma quantidade mínima ou máxima de vezes que estariam utilizando o laptop. Ao ser questionado o contexto atual, sete servidores responderam que utilizam o equipamento quatro vezes ao mês e dois servidores responderam que utilizam dois ou mais vezes por semana. Os depoentes adicionaram a informação que com exceção de alguns professores do $\mathrm{I}^{\mathrm{o}}$ ao $5^{\mathrm{o}}$ ano, os demais precisam agendar a utilização do laptop.

Foi-lhes então questionado qual a necessidade de se agendar o uso dos laptops. Os servidores foram unânimes ao sinalizar que as salas de aula não foram adaptadas com tomadas elétricas para desempenharem as atividades. Alternativamente, para utilizar os equipamentos sem carrega-los previamente, os professores precisam esticar extensões elétricas e dispor os carregadores pelos corredores da sala entre as carteiras dos alunos. Outro fator revelado pelos depoentes é que as baterias dos laptops já não estariam segurando uma carga completa e que a sua autonomia estaria muito reduzida. 
A respeito dos recursos tecnológicos disponíveis para planejarem e executarem suas tarefas, foi solicitado que descrevessem a sua satisfação em relação aos recursos disponibilizados para a utilização no seu trabalho com o laptop. As respostas se concentraram em dois quesitos: acessibilidade à internet e ao próprio laptop.

Quando o laptop começou a ser utilizado em sala de aula com os alunos, a escola dispunha de acesso à internet, porém, o acesso era limitado. As narrativas denotam um desapontamento geral com a limitação da tecnologia disponibilizada aos docentes.

Atualmente, este recurso não está mais disponível porque o acesso à internet foi retirado e não há previsão para sua reativação. No que tange aos equipamentos disponibilizados pelo Projeto UCA para a utilização dos professores e alunos, a crítica recorrente é de que os equipamentos são lentos ao ponto de comprometer o desenvolvimento da aula.

Portanto, os resultados obtidos por meio da pesquisa qualitativa apontam as possíveis causas que teriam influenciado na percepção expressivamente negativa evidenciada no indicador "Recursos tecnológicos que a instituição me oferece para desempenhar minhas atividades", a saber: a dificuldade na utilização dos equipamentos decorrentes da formação dos professores, do suporte tecnológico para o desenvolvimento das atividades e no manuseio dos equipamentos em si.

Ao que concerne à possível influencia das adequações ergonômicas na percepção de QVT, perguntou-se a opinião dos entrevistados a respeito das condições de conforto, segurança e desempenho nos locais de trabalho. Nesta categoria, os respondentes declararam que as salas de aula dispõem apenas de ventiladores e não há nenhuma forma de controle da temperatura ambiente para garantir o conforto térmico. Ao solicitar-se que descrevessem a sensação de conforto térmico no seu local de trabalho utilizando o laptop educacional e considerando a temperatura habitual de trabalho, todos os entrevistados declararam seu descontentamento.

De acordo com as resposta obtidas, as salas de aula são tipicamente quentes e a temperatura aumenta com a utilização dos laptops, sendo que a variação de temperatura é ainda maior com a utilização dos carregadores em sala de aula.

Deste modo, o resultado evidenciado pela análise qualitativa deixa nítido a influencia das condições de conforto, segurança e desempenho no resultado do 
indicador "Adequações ergonômicas no meu local de trabalho para utilização do computador nas atividades que realizo" obtido na pesquisa quantitativa.

Assim sendo, considerando-se os fatores discrepantes entre as escolas pesquisadas, os resultados acima expostos confirmam os indicadores expressivamente negativos obtidos na $\mathrm{I}^{\mathrm{a}}$ fase da pesquisa, detalhando as causas que possivelmente influenciaram as escolhas dos sujeitos da pesquisa.

\section{Considerações Finais}

A utilização do computador em sala de aula, sem dúvida, corresponde a uma quebra de paradigmas no contexto educacional, remodelando e redefinindo as atividades dentro da organização, exigindo o desenvolvimento de novas habilidades e competências não apenas por parte dos trabalhadores, mas também pelos gestores dos sistemas de ensino, pois, em uma análise inicial, essas mudanças tendem a provocar uma ruptura da pratica habitual do trabalhador repercutindo de algum modo na sua percepção de QVT.

Neste estudo, tal entendimento fica diretamente relacionado ao Projeto UCA, na medida em que a análise comparativa das percepções médias de QVT dos servidores das instituições pesquisadas difere especificamente nos indicadores relacionados aos recursos de execução do projeto.

Portanto, considerando a problematização que suscitou este estudo, os resultados tendem a identificar que as percepções de QVT dos servidores de uma escola contemplada pelo Projeto UCA e de outra não participante do referido projeto, diferem tendendo a demonstrar que a participação no Projeto UCA afetou de forma negativa a percepção de QVT dos funcionários da escola no qual o projeto se encontra implantado.

No âmbito das contribuições desse estudo, recomenda-se aos gestores responsáveis em suas diferentes instâncias pela implantação do Projeto UCA na escola analisada, apreciar a possibilidade de revisar o contexto de execução do projeto.

Tendo em vista os resultados obtidos, sugere-se a reprodução desta pesquisa em outros contextos a fim de verificar se as disfunções se repetem, o que poderia significar uma falha no desenho do referido projeto. Também se faz oportuno considerar como um indicador de monitoramento dos resultados do Projeto UCA, a avaliação da qualidade de vida dos trabalhadores, na medida em que este fator pode se tornar determinante ao seu 
sucesso, e já que não há menção da avaliação desses fatores nos relatórios de execução do Projeto UCA.

Diante dos resultados, e considerando uma contribuição para estudos futuros, sugere-se que se desenvolva uma análise da adequação ergonômica do mobiliário, devido à forma como professor e aluno interagem em sala de aula no uso das tecnologias do Projeto UCA, uma vez que os principais fatores que repercutiram de forma negativa na percepção dos pesquisados foram os indicadores "Adequações ergonômicas no meu local de trabalho para utilização do computador nas atividades que realizo", e "Recursos tecnológicos que a instituição me oferece para desempenhar minhas atividades”.

Por fim, torna-se necessário esclarecer que as constatações alcançadas por este estudo não desaprovam o Projeto UCA, mas alerta quanto ao processo de sua implantação, ao serem evidenciados fatores que foram negligenciados e estão influenciando negativamente a percepção de QVT dos servidores lotados na escola investigada.

\section{Referências}

AGRESTI, A. Categorical data analysis. 2 ed. New Jersey: John Wiley, 2002. $5^{26}$ p. ISBN o-47I36093-7

ALMEIDA, M. A. B. Inovação Tecnológica e Desenvolvimento Humano: Aspectos Importantes para a análise da Qualidade de Vida. In: VILARTA et al (Orgs.), Qualidade de vida e novas tecnologias. p.

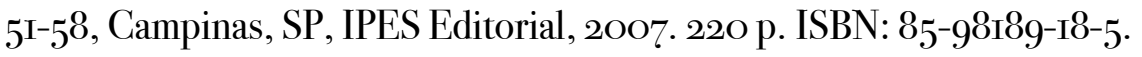

ARRUDA, E. Ciberprofessor - Novas Tecnologias, Ensino e Trabalho Docente. Belo Horizonte: Autêntica/FCHFUMEC, 2004. I36 p. ISBN: 857526r355.

ASSUNÇÃO, A. Á.; OLIVEIRA, D. A. Intensificação do Trabalho e Saúde dos Professores.

Educação e sociedade, v. 30, nº. IO7, p. 349-372, mai./ago.2009. Disponível em:

http://www.scielo.br/pdf/es/v3onio?/o3.pdf Acessado em 25 jul. 2 OI2

AZEVEDO, V. A; KITAMURA, S. Novas Tecnologias, Ergonomia e Qualidade de Vida no Trabalho. In: VILARTA et al (Orgs.), Qualidade de vida e novas tecnologias. p. 85-95, Campinas, SP, IPES Editorial, 2007. 220 p.

BONA, A. S. et al. Aprendizagem pela cooperação no Programa UCA: percepção do professores a partir dos projetos de aprendizagem. RENOTE. Revista novas tecnologias na educação, v. IO, p. I-II, $2 \mathrm{OI} 2$.

CARBONI, I. F. Um Estudo sobre a concepção dos Professores quanto ao uso da Tecnologia da Informação e Comunicação (Tic) No Ensino. Revista Eletrônica Unibero de Produção Científica UNIBERO. v I, p. 3-I7. São Paulo, mar. 20o6. Disponível em: 
http://www.pucrs.br/famat/viali/tic_literatura/artigos/tics/UM\%2oESTUDO_INFORMATICA_ REV.pdf Acessado em o4 mar. 20I4.

CARVALHO-FREITAS, M. N. A Inserção de pessoas com deficiência em empresas brasileiras - Um estudo sobre as relações entre concepções de deficiência, condições de trabalho e qualidade de vida no trabalho. 2007· 3I4 p. Tese (Doutorado em Administração) - Faculdade de Ciências Econômicas, Centro de Pós-graduação e Pesquisas em Administração, Universidade Federal de Minas Gerais, Belo Horizonte, 2007 .

FERNANDES, E. C. Qualidade de vida no trabalho: como medir para melhorar. Salvador: Casa da Qualidade, I996. Io8 p.

GIL, A. C. Métodos e técnicas de pesquisa social. São Paulo: Atlas, I999. IO5 p.

GOMES, F.; ARAÚJO, R. Pesquisa Quanti-Qualitativa em Administração: uma visão holística do objeto em estudo. In: VIII SEMEAD - Seminários em Administração. São Paulo: FEA/USP, 2005· p. o6-o7. Disponível em: www.ead.fea.usp.br/Semead/8semead/resultado/trabalhosPDF/I52.pdf Acesso em: 20 set 2012.

HERÉDIA, V. Novas Tecnologias nos Processos De Trabalho: Efeitos da reestruturação produtiva. Scripta Nova. Revista electrónica de geografía y ciencias sociales. Barcelona: Universidad de Barcelona, 2004, vol. VIII, núm. I7O. http://www.ub.edu/geocrit/sn/sn-I7O-9.htm Acessado em 20 set 2OI2 ISSN: II38-9788.

MALHOTRA, N. Pesquisa de marketing: uma orientação aplicada. 6 ed. Porto Alegre: Bookman, 2OII, 768 p. ISBN 8577809757.

MEDEIROS, L.; FERREIRA, M. C. Qualidade de Vida no Trabalho: uma revisão da produção científica de I995-2009. Gestão Contemporânea, Porto Alegre, ano 8, n. 9, p. 9-34, jan./jun. 2OII.

NETZ, S. R. Novas Tecnologias da Informação: suas influências no trabalho bancário. In: XII Congresso Brasileiro de Sociologia, 2005, Belo Horizonte. XII Congresso Brasileiro de Sociologia GTig: 2005. I8 p.

OLIVEIRA, G. A ERGONOMIA NO TRABALHO E AS NOVAS TECNOLOGIAS. In: VILARTA $e t$ al(Orgs.), Qualidade de Vida e Novas Tecnologias. p. I6I-I67, Campinas, SP, IPES Editorial, 2007. 220 p. ISBN: 85-98189-I8-5.

OLIVEIRA, W. As tecnologias da informação e comunicação e a intensificação do trabalho docente. Educação, Formação \& Tecnologias, v. 3, n. I, 20IO. p. 84 - 95. ISSN-e: I646-933X. Disponível em: http://dialnet.unirioja.es/servlet/autor?codigo=26Io633 Acesso em: 27 set 2012.

OLPC BRASIL. One laptop per child Brasil. Disponível em: http://www.olpc.org.br Acesso em: 2 mar. 2012.

PILATTI, L. A. QUALIDADE DE VIDA E TRABALHO: PERSPECTIVAS NA SOCIEDADE DO CONHECIMENTO. In: VILARTA et al(Orgs.), Qualidade de Vida e Novas Tecnologias. p. 4I-5O, Campinas, SP, IPES Editorial, 2007. 220 p. ISBN: 85-98189-18-5.

SANTOS, M. B. F. dos; BORGES, M. K. Alterações no cotidiano escolar decorrentes da implantação de laptops educacionais. Revista E-Curriculum, São Paulo, v 4, n. 2, p. I-2I, jun. 20o9. Disponível em: http://revistas.pucsp.br/index.php/curriculum/article/view/3232/2I5O Acesso em: I6 fev. 2 OI2. 
SCHNEIDER, F. ; SANTAROSA, L. C.; CONFORTO, D. Cidade Um Computador por Aluno UCA Total: a identificação de situações inclusivas na totalidade. Novas Tecnologias na Educação, Porto Alegre, v. 9, n. I, p. I-IO, jul. 20II. ISSN ı679-I9ı6. Disponível em: http://seer.ufrgs.br/renote/article/view/2I922/I2722 Acesso em: 27 out. 2 OI2.

SOUZA, F. K. N.; ZIVIANI, F. A qualidade de vida no trabalho correlacionada a pratica da ginástica laboral. Revista Científica do Departamento de Ciências Jurídicas, Políticas e Gerenciais do UNI-BH. Belo Horizonte, vol. III, n. I, jul-20IO. ISSN: I984-27I6. Disponível em: www.unibh.br/revistas/ecivitas/ Acessado em oI set. 2012.

UCA. Projeto Um Computador Por Aluno. Disponível em: http://www.uca.gov.br Acesso em: 30 out. $2 \mathrm{OI2}$.

WALTON, R. E. Quality of Work Life: What is it? Sloan Management Review. v. I, p. II-2I, I973. 